\title{
DIREITO ECONÔMICO DA ENERGIA ELÉTRICA: A VARIAÇÃO DA TARIFA E AS FALHAS DE MERCADO
}

\author{
Alcides Goelzer de Araújo Vargas e Pinto* \\ Giovanna Rosa Perin** \\ Francisco Carlos Duarte***
}

SUMÁRIO: Introdução; 2 Sistema Econômico e seus Pré-Questionamentos Fundamentais; 30 Mercado e suas Falhas; 3.1 AFalha de Mercado da Externalidade; 4 ICMS: Uma Importante Forma de Arrecadação de Renda pelos Estados; 5 A Tarifa de Energia Elétrica e seu Reflexo nos Orçamentos Estaduais; 6 Considerações Finais; Referências.

RESUMO: O artigo analisa a sucessiva variação da tarifa da energia elétrica no Brasil e sua relação com as falhas de mercado. Para tal fim, foi necessária a utilização da metodologia teórico-descritiva, buscando a compreensão, do ponto de vista jurídicoeconômico, das normas que regulam a tarifa energética, e de pesquisa bibliográfica correspondente ao tema, bem como do método indutivo, pois se trata de assunto atual e sem entendimento fixado, de essencial importância para preencher as lacunas daquilo não debatido pela sociedade. Assim, será necessário examinar algumas noções doutrinárias sobre os modelos básicos de sistemas econômicos, verificando, inclusive, o surgimento do mercado. O artigo discorrerá sobre todas as falhas de mercados existentes, dando ênfase para a da externalidade, verificando que a mesma pode ter efeitos positivos e negativos. Estudará, ainda, o ICMS e a sua importância para os estados. Finalmente compreender-se-á que a medida governamental que reduziu a conta de luz possuía mais externalidades positivas do que negativas, mas que a falta de um planejamento nacional fez com que houvesse aumento da energia elétrica em poucos meses o que prejudica todos os cidadãos brasileiros.

PALAVRAS-CHAVE: Desenvolvimento Econômico; Energia Elétrica; Falhas de Mercado.

\section{THE ECONOMIC RIGHT TO ELECTRICIT Y: BILL VARIATIONS AND MARKET FAILURES}

ABSTRACT: The successive variation in electricity bills in Brazil and its relationship

\footnotetext{
" Advogado; Mestrando em Direito Econômico pela Pontifícia Universidade Católica do Paraná-PR (PUC-PR); Pós-graduando em Direito Empresarial pela Fundação Getúlio Vargas de São Paulo (GV Law); E-mail: pinto_alcides@hotmail.com

** Advogada; Pós-graduanda em Direito Empresarial pela Fundação Getúlio Vargas de São Paulo-SP (GV Law).

*** Procurador do Estado do Paraná; Pós doutor pela Universidade Técnica de Lisboa - Portugal, pela Universitá di Lecce - Itália e pela Universidad de Granada - Espanha.
} 
to market failures are analyzed. The theoretical and descriptive method was employed to understand the rules regulating electricity bills, from the juridical and economical point of view, and the bibliographic research on the theme. The induction method is also applied since it deals with current affairs lacking a fixed understanding but of great importance to fill the gaps about what is not debated in society. Several doctrinal notions on the basic models of economic systems were examined to verify the emergence of the market, among other things. The essay focuses on market failures with special emphasis on externality with its positive and negative effects. The ICMS tax and its importance for the Brazilian states are also analyzed. The government's rule for reduction in electricity bill had more positive than negative externalities even though lack of planning increased electric energy consumption in a short period and jeopardized the entire population.

KEY WORDS: Market Failures; Economic Development; Electric Energy.

\section{DERECHO ECONÓMICO DE LA ENERGÍA ELÉCTRICA: LA VARIACIÓN DE LA TARIFA Y LOS FALLOS DEL MERCADO}

RESUMEN: El artículo analiza la sucesiva variación de la tarifa de energía en Brasil y su relación con los fallos del mercado. Para tal, fue necesaria la utilización de la metodología teórico-descriptiva, buscando la comprensión, del punto de vista jurídico-económico, de las normas que reglamentan la tarifa energética y de la investigación bibliográfica correspondiente al tema, bien como del método inductivo, pues se trata de asunto actual y sin entendimiento fijo, de esencial importancia para rellenar las lagunas de lo que no es debatido por la sociedad. Así, será necesario examinar algunas nociones doctrinarias sobre los modelos básicos de sistemas económicos, verificando, incluso, el surgimiento del mercado. El artículo tratará sobre todos los fallos de mercado existentes, enfatizando la externalidad y sus efectos positivos y negativos. Estudiará, todavía, el ICMS y su importancia para los estados. Finalmente, se comprenderá que la medida gubernamental responsable por la reducción de la tarifa de luz eléctrica poseía más externalidades positivas que negativas, sin embrago, la falta de planeamiento nacional hizo con que ocurriera un aumento de la misma en pocos meses - lo que perjudica todos los ciudadanos brasileños.

PALABRAS-CLAVE: Fallos de Mercado; Desarrollo Económico; Energía Eléctrica. 


\section{INTRODUÇÃO}

O presente estudo visa realizar uma análise crítica sobre as consequências e implicações da redução da tarifa de energia elétrica ocorrida em 2013, analisando, ainda, o impactante aumento tarifário no ano de 2015.

Para tal, necessário se faz a compreensão dos Sistemas Econômicos existentes e verificação de qual seria o ideal a ser adotado pelos Estados. Busca-se, com isso, justificar a atuação estatal na correção das falhas de mercado, principalmente no que diz respeito aos efeitos negativos das medidas governamentais.

Assim, no primeiro tópico, é definido o Sistema Econômico e seus três modelos fundamentais verificados pela doutrina, sendo eles: (i) tradição; (ii) autoridade; e (iii) autonomia, assimilando que esse último é o que melhor se amolda à realidade brasileira, pois obriga a separação entre as tomadas de decisões de cunho político e econômico.

O tópico seguinte explica o surgimento das falhas de mercado, evidenciado que referidas falhas não são meras justificativas para atuação estatal na economia, já que realmente existem. Assim, importantíssimo explicar cada falha de mercado, com ênfase na externalidade, ou seja, quando um terceiro, alheio à relação econômica, sofre os efeitos direttos ou indiretos, positivos ou negativos, da interação econômica de outros agentes.

O próximo tópico, por sua vez, conceitua o Imposto sobre Circulação de Mercadorias e Serviços (ICMS), explicando que esse imposto é importantíssimo para o desenvolvimento regional, pois sua arrecadação não é destinada à União, mas para cada Estado brasileiro.

Menciona-se, posteriormente, que uma das principais rendas estaduais advém da incidência do ICMS sobre o fornecimento de energia elétrica, que é calculada através de uma fórmula fornecida pelo Departamento Nacional de Águas e Energia Elétrica, sendo ela: ICMS = Fornecimento x [1/(1-Alíquota) $]$ - 1, representando, em média, $9 \%$ (nove por cento) da arrecadação de todos os impostos pelos Estados.

O tópico seguinte demonstra que a imposição federal que reduziu a tarifa de energia elétrica em 2013 ocasionou forte impacto na base arrecadatória dos governos estaduais, pois as arrecadações de ICMS das contas de energia elétrica 
diminuíram, evidenciando que há falha de mercado da medida supramencionada.

Por outro lado, explica que o corte na conta da energia elétrica poderia representar verdadeiro incentivo para a atividade econômica, já que o consumidor, ao utilizar menor quantia de seu orçamento com o adimplemento da conta de luz, passaria a destinar tal excedente na aquisição de serviços e produtos do comércio em geral, gerando, consequentemente, maior arrecadação de ICMS pelos Estados.

Ocorre que os Estados, desesperados pela diminuição momentânea de suas arrecadações, majoraram a alíquota de ICMS de outros produtos e serviços, inclusive em alimentos, materiais de limpeza e artefatos de uso doméstico, confirmando a verificação da externalidade negativa da medida governamental.

Como se pode perceber, a redução da conta de energia elétrica ocorrida em 2013 poderia beneficiar tanto os Estados como os cidadãos, entretanto o Governo Federal deixou de subsidiar a energia elétrica, repassando os custos para os consumidores, que se viram diante de onerosas contas de energia, fazendo com que tivessem que reduzir os gastos em outros produtos e serviços para adimplir o valor dessas faturas.

Por fim, o último tópico conclui a matéria, demonstrando que a medida governamental de 2013 mais pareceu como uma política eleitoreira do que uma política pública em benefício da população, revelando que a intervenção estatal na economia pode ocasionar graves falhas de mercado.

\section{SISTEMA ECONÔMICO E SEUS PRÉ-QUESTIONAMENTOS FUNDAMENTAIS}

Antes de aprofundar o estudo sobre as falhas de mercado, necessário se faz a compreensão do Sistema Econômico e de seus três modelos fundamentais, pois é dentro destes modelos que as falhas de mercado têm origem.

Desta maneira, cumpre destacar o conceito de Sistema Econômico que, doutrinariamente, pode ter duas acepções: uma com sentido amplo e genérico e outra com um sentido técnico, entretanto ambas determinam que Sistema Econômico tem por objetivo permitir uma administração eficaz dos recursos escassos, evitando, desta forma, o desperdício.

Genericamente falando, o Sistema Econômico pode ser definido como 
sendo o "conjunto das atividades econômicas de uma dada comunidade" ${ }^{\text {, enquanto }}$ tecnicamente significa "um particular conjunto orgânico de instituições, através do qual a sociedade irá enfrentar ou equacionar o seu problema econômico"2, ou seja, "é o conjunto de instituições destinado a permitir a qualquer grupo humano administrar seus recursos escassos com um mínimo de proficiência, evitando o quanto possível de desperdício ou malbaratamento"3.

Portanto, verifica-se que, no sentido técnico, o Sistema Econômico é um conjunto de ações tomadas pelo grupo que administra determinado espaço territorial e que possui como objetivo a maximização da eficiência na utilização dos recursos escassos, de forma a trazer maior benefício para a sociedade. Ele é o conjunto de princípios e técnicas com os quais os problemas da economia são endereçados, como, por exemplo, o problema da escassez dos bens e recursos e o da alocação dos recursos produtivos limitados.

O Sistema Econômico existe para cumprir, basicamente, três funções: (i) estabelece critérios para que o grupo que administra delimitado espaço territorial tome a melhor decisão para o caso concreto; (ii) estabelece organismos que são aptos a facilitar a coordenação das tomadas de decisões; e (iii) constitui uma forma de controle das decisões que serão tomadas pelo grupo.

Destaca-se a definição trazida por Bresser-Pereira:

Um sistema é sempre um conjunto de elementos articulados entre si de forma a constituir um todo. Essa articulação ou coordenação dos elementos obedece a uma lógica, que é a da sobrevivência, quando se trata de sistema vivo. Quando se trata de um sistema social, o objetivo mínimo é igualmente a sobrevivência, ou a segurança, mas como é formado de agentes racionais dotados de vontade, há um objetivo econômico adicional: o bem-estar. Esta afirmação não é arbitrária: com o trabalho, que é o elemento básico de qualquer sistema econômico, o homem visa melhorar seu padrão de vida. Quando, finalmente, se trata de um sistema social dotado de um Estado moderno e democrático, ou seja, dotado de um instrumento de ação coletiva, o bem-estar deixa de ser um objetivo implícito e passa a ser explícito. Os governos dos Estados-nação, apoiados e legitimados por seu povo ou nação, passam a desenvolver estratégias buscando o desenvolvimento econômico. A lógica do sistema passa a ser o de-

1 NUSDEO, Fábio. Curso de economia: introdução ao direito econômico. $7^{\mathrm{a}}$ ed. rev. atual. e ampl. - São Paulo: Ed. Revistas dos Tribunais, 2013. p.100.

2 NUSDEO, Fábio. op. cit., p. 100.

3 Idem. 
senvolvimento. ${ }^{4}$

O Sistema Econômico, por ser o conjunto de tomadas de decisões que leva em consideração a maior eficiência ao aplicar os recursos escassos, baseia-se em três questionamentos-chave: o que produzir, como produzir e para quem produzir.

Não faria sentido um país produzir algo que não é desejado por ninguém, ou seja, que não tenha comprador. Por isso é importantíssimo saber o que produzir. Da mesma forma, o produtor precisa saber como produzir este produto demandado pelo mercado, quais as melhores técnicas aplicáveis, os modos de produção e a melhor forma de utilização dos recursos escassos. Assim como resta necessário estabelecer um critério de distribuição do produto, ou seja, qual parcela da sociedade será a destinatária final para consumo do produto.

Depois de abordadas as características, qualidades e funções do Sistema Econômico, é necessário compreender os três tipos de modelos de Sistemas Econômicos existentes na doutrina, sendo eles: tradição, autoridade e autonomia.

O Sistema Econômico da tradição é baseado nos usos e costumes passados de uma geração para a outra, possuem a tendência de se manter inertes, ou seja, são imutáveis. Trata-se de um sistema em que a sociedade se organiza e opera de forma tradicionalista, onde as técnicas de produção são transmitidas de uma geração para outra, sendo que a própria sociedade, por intermédio de seus indivíduos, decide o que produzir, quanto produzir e para quem produzir.5

Nesse Sistema Econômico, as atividades econômicas possuem papel secundário e as atividades principais são, por exmplo, a religião, a dança e o esporte.

Quanto ao questionamento necessário para a formação de um Sistema Econômico (O que produzir? Como produzir? Para quem produzir?), o Sistema da Tradição acredita ser útil a produção dos bens consumidos e adotados pela sociedade que remetem aos padrões anteriormente consagrados, como roupas, alimentos e utensílios tradicionais, reiterando os bens e serviços já consagrados, que devem ser feitos com métodos e técnicas herdados pelas gerações anteriores. ${ }^{6}$

Portanto, esse Sistema tem sustentação no pressuposto psicológicocomportamental do consenso dos valores e costumes mantidos pela comunidade, ou seja, a sociedade define os padróes fundamentais.

Este estilo de Sistema Econômico era muito utilizado na época medieval,

BRESSER-PEREIRA, Luiz Carlos. Sistema Econômico Brasileiro. Conjuntura Econômica, v. 59, n. 4, abril 2005 : p. 16-17.

5 NEVES, Luís Gustavo Bregalda. Sistemas Econômicos e a Era Moderna. Disponível em: < http://www.mundojuridico.adv.br/sis_artigos/artigos.asp?codigo=288>. Acesso em: 12 jun. 2015.

6 NUSDEO, Fabio. op. cit., p. 104. 
nos feudos e nos burgos, ou seja, dentro de uma sociedade dividida em setores, em que há evidente divisão das camadas sociais. O desenvolvimento das feiras mercantis fez com que este sistema entrasse em colapso na Idade Moderna.

Outro modelo de Sistema Econômico é o da Autoridade e que melhor se define como sendo o modelo onde "as decisões econômicas são avocadas pelo poder político e nele centralizados" ". Evidencia-se, portanto, que as decisões econômicas deste modelo são centralizadas pelo poder político.

É no sistema da autoridade que encontramos a figura do Estado centralizador, possuidor de todo o poder para a tomada de decisões, tendo elas teor econômico ou não.

Nesse modelo de Sistema, o questionamento do que produzir, para quem produzir e como produzir são decisões tomadas pelo orgão político decisor que representa o Estado. Este órgão determina metas de produção com base em sua avaliação sobre as necessidades a serem atendidas, mediante um plano econômico; o modo de produção também está revelado neste plano econômico, que leva em conta a escassez ou abundância de insumos.

Quanto à distribuição da produção, esta é direta, com a entrega de bens conforme mérito ou necessidade, assim como também é indireta, ou seja, o governo determina a hierarquia salarial e o valor dos bens a serem percebidos por cada um. Portanto, resta fácil perceber que a figura do Estado centralizador neste sistema econômico o torna o único produtor, vendedor e empregador, controlando toda a economia.

O pressuposto psicológico-comportamental que sustenta esse Sistema demanda da crença positiva, voltada na virtude do planejamento e na confiança da sociedade no órgão decisório, assim como há uma crença negativa, ou seja, uma falta de credibilidade em outro tipo de sistema mais eficiente do que o baseado na centralização integral das tomadas de decisões. Neste contexto:

Essencialmente vem a ser a crença nas virtudes e na racionalidade do planejamento e a confiança nos critérios do órgão planejador, seja este um homem, um grupo, [...] ou ainda, na capacidade do todo social de levar àquele órgão as suas expectativas, os seus objetivos, as suas prioridades, num contexto de solidariedade social. Mais, porém, do que uma crença positiva, isto é, nas virtudes e possibilidades do planejamento, existe uma crença negativa, ou seja, uma descrença no outro critério alternativo de organização econômica, fundado na liberdade e na autonomia das decisões tomadas descentralizadamente, um temor de as prioridades sociais do Estado serem suplantadas

\footnotetext{
NUSDEO, Fabio. op. cit., p. 108.
} 
pelas prioridades de lucro do empresariado e outros sentimentos ou posições ideológicas análogas. ${ }^{8}$

Por fim, aborda-se o último modelo de Sistema Econômico: o da Autonomia. Neste Sistema há uma forte separação entre as tomadas de decisões de cunho político e econômico, ou seja, as decisões políticas continuam sendo tomadas pelo órgão estatal (Estado), enquanto que as decisões de cunho econômico passam a ser tomadas pelos particulares, ou seja, aos agentes econômicos autônomos.

O pressuposto psicológico-comportamental está baseado no hedonismo, ou seja, no sentimento de que o homem visa sempre a maximizar os resultados de suas ações, de forma a obter o máximo de retribuição ou de remuneração, desempenhando o menor esforço físico. Trata-se da chamada lei da maximização dos resultados.

Com relação aos questionamentos econômicos sobre o que produzir, como produzir e para quem produzir é respondido pelos preços das mercadorias, tendo em vista o objetivo dos agentes em maximizar lucro. Desta forma, quem decide o que produzir é a população. Entretanto, quem implementa a decisão são os donos dos fatores de produção.

Os meios de produção de como produzir estão nas mãos dos produtores, que estão à procura de meios e técnicas de produção que maximizem o lucro, esperando utilizar insumos mais baratos e receber preços elevados pelos bens produzidos.

O destinatário dos bens depende do mercado, eis que este atribui o preço do produto estipulado pela própria demanda, dependendo dos gostos e necessidades dos consumidores.

Este é o modelo de sistema ideal a ser adotado pelos Estados, pois há uma notória separação entre o setor político e o econômico da sociedade, sendo que o pressuposto psicológico do espírito hedonista é capaz de proporcionar um melhor emprego dos insumos e das técnicas, havendo, consequentemente, maior lucro.

\section{O MERCADO E SUAS FALHAS}

Anteriormente realizamos uma análise teórica acerca dos três modelos de 
Sistemas Econômicos existentes, sendo destacado que no sistema da autonomia há o surgimento da figura do mercado?.

Desta maneira, o Sistema Econômico Autônomo é baseado pela livre atuação do mercado, onde não há intervenção estatal e busca-se maximizar a eficiência das tomadas de decisões realizadas pelos particulares dentro do mercado.

A atuação estatal apenas se justifica quando ocorre o surgimento das falhas de mercado, advindas da ineficiência do mercado em atender as inúmeras vontades.

O surgimento das falhas de mercado pode assim ser contextualizado:

[...] as falhas de mercado e imperfeições do mercado foram se positivando ao longo de cerca de 150 anos quando se tentou ou se imaginou poder operacionalizá-lo com base naquela estrutura institucional relativamente simples ou até simplória, assentada no tripé: constituição, códigos de Direito privado e poder de polícia. Tripé sem dúvida portentoso pela dutibilidade, lógica e racionalidade com que concebeu a forma e as garantias legais para captar e disciplinar todo o emaranhado das relações econômicas internas e mesmo internacionais, mas incapaz de lidar com a vida econômica real em toda a sua complexidade. Foi a época na qual, no dizer de Max Weber, a lei apresentava uma racionalidade puramente formal, não lhe interessando as condições pessoais ou sociais dos por ela abrangidos, nem a maior ou menor desejabilidade dos resultados das relaçóes estabelecidas sob sua égide. ${ }^{10}$

Portanto, precisa-se saber se o mercado é eficiente para então vislumbrar a existência ou não das falhas no mercado. Existem dois tipos de eficiência dentro do estudo de Direito Econômico, a (i) eficiência alocativa, que busca a melhor situação econômica para todos os agentes envolvidos; e a (ii) eficiência distributiva, que propõe a equidade e a distribuição de renda, mesmo que possa prejudicar alguém, mas que vise melhorar a situação de muitos outros.

Além da eficiência alocativa e distributiva, resta necessário que o mercado promova a competição perfeita entre os produtores. Para que um mercado seja considerado perfeitamente competitivo, é imperioso que os produtos de diversos vendedores sejam equivalentes iguais nas suas qualidades e preço. Também é cogente que os produtores e os fornecedores sejam tomadores de preço (price-takers), eis que, individualmente, eles não têm poder de mercado suficiente para influenciar o

\footnotetext{
9 Mercado é o local onde compradores e os vendedores se encontram para trocar mercadorias por outras mercadorias ou dinheiro.

${ }^{10}$ NUSDEO, Fábio. op. cit., p. 142.
} 
preço; assim como é forçoso que todos os recursos sejam perfeitamente móveis e que as empresas entrem e saiam de forma livre nesse tipo de mercado; e, por fim, que o fluxo de informações seja perfeito, não havendo uma concorrência desleal em virtude de um agente econômico saber mais que outro. ${ }^{11}$

Neste contexto, falha de mercado se conceitua como sendo as circunstâncias específicas que levam um sistema de livre mercado à alocação ineficiente de bens e serviços. As imperfeições de mercado são oriundas de desvios de condições do mercado competitivo, verificadas pela atitude de indivíduos privados, que, na busca por maximizar interesses próprios, acabam tomando atitudes que não são contrárias aos interesses sociais. ${ }^{12}$

Assim, as falhas de mercado devem ser associadas com assimetria informacional, estruturas não competitivas dos mercados, problemas de monopólio natural, externalidades e bens públicos.

Há quem diga que o tema falhas de mercado é apenas uma justificativa do Estado para intervir na Economia. Neste âmbito, cita-se:

Um dos argumentos mais utilizados como tentativa de justificar o intervencionismo do Estado no processo de mercado é a alegação de que se tornam necessárias as correções, por parte do poder público, das imperfeições e falhas apresentadas pela economia de livre mercado. O objetivo deste capítulo é mostrar que o referido argumento peca duplamente: primeiro, por sua falaciosidade e, segundo, por sua periculosidade. Com efeito, a posição da Escola Austríaca a respeito das tão propaladas "falhas de mercado" fundamenta-se em duas proposições básicas: a de que a maioria dessas falhas, quando estudadas criteriosamente, revelam-se resultantes de defeitos extramercados, de natureza institucional e a de que, quando ocorrem de fato falhas de mercado, elas tendem a ser amplificadas (e não eliminadas), como conseqüência da intervenção governamental. ${ }^{13}$

Ocorre que as falhas de mercado realmente existem e a primeira delas a ser destacada pela doutrina é chamada de assimetria informacional, existente em situações em que um dos agentes econômicos detém um nível de informação diferente do outro indivíduo, de forma a levar vantagem. Assim, um dos agentes possui informação privilegiada, tomando suas ações com base nesta informação e se

${ }_{11}$ SEIDENFELD, Mark. op. cit., p. 35.

12 SEIDENFELD, Mark. op. cit., p. 61.

${ }^{13}$ IORO, Jorge Ubiratan. Economia e Liberdade: a escola austríaca e a economia brasileira. Cap. 5 - Falhas de Mercado Versus Falhas de Governo. Disponível em: < http://www.mises.org.br/SearchByAuthor.aspx?id=192>. Acesso em: 15 jun. 2015. 
beneficiando por este motivo.

Outra falha destacada é a (i)mobilidade dos fatores de produção, como capital e trabalho, que podem não possuir mobilidade suficiente para evitar a ineficiência do mercado. Assim, sua regulação através de práticas governamentais se faz necessária e que pode ocorrer, por exemplo, através do fomento.

Temos, ainda, a falha da concentração, situação em que há a criação de monopólio no mercado, ou seja, a existência de apenas um agente econômico que acaba atuando de forma abusiva. Desta falha surgiram inúmeras normas jurídicas, como as concorrenciais e antitrustes.

Destaca-se a falha denominada de custos de transação. Ela reflete o pensamento do agente econômico em analisar o custo da mudança antes mesmo de efetivar a transação. Trata-se dos custos despendidos com determinada alteração, a exemplo de gastos materiais, como valores com advogados, negociações, e gastos imateriais, como sentimentos.

Esta falha pode levar a outra falha, a da concentração, eis que há a tendência do agente econômico contratante não modificar o agente contratado em virtude do alto desempenho e custo para transacionar com um novo agente. Os custos de uma transação são altos, sendo capazes de inibir o contratante a iniciar uma nova transação com outro agente desconhecido, o que acaba levando à concentração de mercados nas mãos de poucos.

A última falha que deve ser destacada neste tópico é a dos bens públicos, que são os bens cuja propriedade, do ponto de vista social e jurídica, não é bem definida, de modo que os agentes econômicos não possuem interesse em sua conservação ou reprodução econômica. Essa, inclusive, é a conceituação apresentada por Jorge Ioro:

São definidos como aqueles bens que geram benefícios para todos, mas cujos custos não podem ser distribuídos, pela simples razão de que não se pode excluir do consumo os indivíduos que se recusam a pagar por eles. Tal costuma ser o caso de estradas, parques públicos, policiamento, defesa nacional, meio ambiente, etc. A diferença mais importante entre os bens públicos e os demais é que os benefícios por eles gerados, não podendo ser alocados entre os beneficiários de acordo com algum princípio econômico, devem ser objeto de decisões políticas, o que significa que o Estado é quem deve produzi-los, buscando financiamento na tributação, na inflação e na dívida interna ou externa. ${ }^{14}$

\footnotetext{
${ }_{14}$ IORO, Jorge Ubiratan. Economia e Liberdade: A Escola Austríaca e a Economia Brasileira. Cap. 5 - Falhas de Mercado Versus Falhas de Governo. Disponível em: <http://www.mises.org.br/SearchByAuthor.aspx?id=192>. Acesso em: 15 jun. 2015.
} 
Como se vê, a titularidade jurídica deste bem não é claramente delimitada, não havendo incentivo para conservação dos bens públicos. É exatamente diante desta falha que a corrupção aparece, pois há percepção de que o bem, pelo simples fato de ser público, acaba não sendo de ninguém, quando na verdade é de todos.

A atuação estatal para combater essa falha está baseada na regulação que obriga o agente a conservar o bem público como se fosse extensão do seu conjunto patrimonial, proporcionando, com isso, o interesse da coletividade.

Por fim, destaca-se que a última falha de mercado é da externalidade, que será analisada de forma mais detalhada para então podermos verificar sua relação com a variação da tarifa energética nos últimos anos.

\subsection{A FALHA DE MERCADO DA EXTERNALIDADE}

A falha de mercado da externalidade ocorre quando um terceiro, alheio à relação econômica, sofre efeitos diretos ou indiretos, positivos ou negativos, da interação econômica de outros agentes. Trata-se, portanto, do prejuízo ou benefício que não é internalizado pelos indivíduos que interagem na relação econômica, impondo consequências a terceiros.

Nusdeo explica que a falha de concentração econômica representa uma falha de estrutura no mercado, enquanto que a externalidade representa uma falha de sinal neste mercado. ${ }^{15}$ Vejamos:

Os custos e os benefícios de qualquer atividade devem ser apropriados pelas unidades responsáveis, quer produtoras, quer consumidoras. Quando tal pressuposto deixa de ocorrer, alguns fatores escassos passam a ser utilizados por terceiros sem ter a sua escassez devidamente sinalizada. ${ }^{16}$

Em outras palavras, externalidade é o efeito, tanto positivo (benefício), quanto negativo (custo), causado a outra pessoa que esteja fora da relação econômica que originou tal "efeito colateral", ou seja, externalidade é o impacto de um agente sobre um terceiro que não participou da ação econômica.

O estudo das externalidades foi primeiramente trazido pelo economista Ronald Coase, pertencente à Universidade de Chicago, em seu livro intitulado "O Problema do Custo Social", obra prima que lhe consagrou o prêmio Nobel de

\footnotetext{
$\overline{15}$ NUSDEO, Fabio. op. cit., p. 155.

${ }^{16}$ Idem.
} 
Ciências Econômicas em 1991. ${ }^{17}$

Coase criou um Teorema, denominado de "Teorema de Coase", que determina até que ponto o mercado privado é eficaz em lidar com as externalidades, sendo que a falha ora estudada surge dos custos de transação. ${ }^{18}$ Nestes termos, seu teorema é bem definido por Mankiw:

Os agentes privados podem solucionar os problemas das externalidades entre si, desde que os custos de transação não sejam excessivos. Qualquer que seja a distribuição inicial dos direitos, as partes interessadas sempre podem chegar a um acordo pelo o qual todos ficam numa situação melhor. ${ }^{19}$

Como já citado, a externalidade pode provocar dois efeitos diversos: positivo ou negativo. O primeiro ocorre quando o efeito a terceiro é um benefício, já o negativo, também chamado de custo social, ocorre quando o terceiro acaba sendo prejudicado sem ter relação alguma com a transação econômica originária.

Um clássico exemplo de externalidade negativa é verificado pela população de uma cidade onde há elevado grau de poluição ocasionada por uma usina existente na região. A própria ação de poluir causa efeitos negativos aos cidadãos que terão que respirar tal ar impuro, sendo que não possuem relação econômica nenhuma com a geração da poluição. Neste caso, o custo social é maior que o custo privado, devendo tal falha ser sanada.

Evidencia-se, portanto, a importância do Estado em intervir, sendo aceitável a cobrança de taxas, por exemplo, sobre a atividade da usina, de forma a imputar ao agente poluidor o custo decorrente da externalidade negativa que é causador. Assim, busca-se a equivalência do custo social com o custo privado.

Vale apontar que no caso da usina poluidora também é perceptível a externalidade positiva, pois ela gera empregos aos cidadãos da região, criando benefícios indiretos a terceiros, alheios à relação econômica.

Cumpre destacar, ainda, que essa falha de mercado também pode ser promovida pelo Estado, ao incentivar de forma fiscal, por exemplo, a instalação de outras usinas em regiões inóspitas e frágeis economicamente, de forma a propiciar a criação de novos empregos naquela região carente.

\footnotetext{
7 THE RONALD COASE INSTITUTE. Biografia. Disponível em: < https://www.coase.org/aboutronaldcoase. htm >. Acesso em: 19 jun. 2015.

${ }_{18}$ MANKIW, N. Gregory. op. cit., p. 210.

19 Ibidem., p. 211.
} 
Assim, após compreendermos as falhas de mercado, em especial a da externalidade, passamos a analisar a cobrança do ICMS, verificando, então, se tal imposto possui relação, direta ou indireta, com a conta da energia elétrica paga pelos consumidores, estudando, por fim, se a majoração do ICMS trata-se de uma externalidade advinda da medida governamental relacionada à tarifa energética.

\section{ICMS: UMA IMPORTANTE FORMA DE ARRECADAÇÃO DE RENDA PELOS ES- TADOS}

ICMS é a sigla que identifica o Imposto sobre Operações relativas à Circulação de Mercadorias e sobre Prestações de Serviços de Transporte Interestadual e Intermunicipal e de Comunicação. É um tipo de imposto instituído por cada um dos Estados brasileiros e, também, pelo Distrito Federal, conforme permite a Constituição Federal de 1988.

Toda relação econômica que envolva a circulação, ou seja, compra e venda de bens ou serviços, gera arrecadação do ICMS ao Estado onde ocorrera tal relação.

Esse imposto pode ser seletivo, sendo que, às vezes, a tributação depende do tipo de mercadoria ou de serviço da relação econômica. Na maioria dos casos, o ICMS, que é embutido no preço, corresponde ao percentual de 18\%. Entretanto, alimentos básicos como arroz ou feijão, o ICMS é menor, cobrado, em média, 7\%, enquanto produtos como cigarros e perfumes percebem $27 \%$ de imposto. ${ }^{20}$

O ICMS, portanto, é uma nítida forma do Estado intervir no livre e autônomo mercado. Ele serve como uma importantíssima ferramenta ao Estado para intervir no consumo, servindo, inclusive, para sanar falhas de mercado.

Trata-se de um imposto não cumulativo, compensando-se o valor devido em cada operação ou prestação com o montante cobrado anteriormente. Em cada etapa da circulação de mercadorias e em toda prestação de serviço sujeita ao ICMS deve haver emissão da nota fiscal ou cupom fiscal, sendo cobrado o imposto em todas as etapas até chegar ao consumidor final. ${ }^{21}$

Como se vê o imposto em questão tem como fundamento a intervenção

\footnotetext{
${ }^{20}$ SECRETARIA DA FAZENDA DO ESTADO DE SÃO PAULO. Banco de dados. Disponível em: < http://www. fazenda.sp.gov.br/oquee/oq_icms.shtm >. Acesso em: 19 jun. 2015.

${ }^{21}$ SILVEIRA, Paulo Antônio Caliendo Velloso da. Direito Tributário e Análise Econômica do Direito: uma visão crítica. Rio de Janeiro: Elsevier, 2009.
} 
estatal na economia, mas também é a maior fonte de recursos financeiros para os Estados brasileiros, realçando sua importância para o desenvolvimento regional.

AConstituição Federal possui diversos dispositivos que tratam deste imposto, deixando evidente sua complexidade perante o sistema tributário nacional. ${ }^{22} \mathrm{~A}$ Constituição determina, inclusive, que o ICMS deva ser calculado através de uma base de cálculo expressa em lei, com a finalidade exclusiva de mapear critérios para determinação, em cada obrigação tributária, sendo que neste elemento quantitativo estarão presentes os fatores de composição do valor pecuniário, o objeto da prestação. Carvalho é claro neste sentido:

Repousa aqui o sainete próprio da categoria obrigacional, em face das demais relações tributárias, de modo que o grupo de indicações que o intérprete obtém, na leitura atenta dos textos legais, e que lhe torna possível precisar, com segurança, a exata quantidade devida a título de tributo, é aquilo que chamo de elemento quantitativo do fato jurídico tributário. ${ }^{23}$

O ICMS é um tipo de tributação sobre o consumo, em que há cobrança indireta do tributo. Vale mencionar que ele não é cobrado dos comerciantes ou industriais, mas acrescentado no preço final das mercadorias ou dos serviços prestados, sendo que quem realmente arcará com tal despesa é o consumidor. ${ }^{24}$

Esse imposto incide, inclusive, sobre o fornecimento de energia elétrica, o que é instituído por lei estatal. No Estado de São Paulo, por exemplo, o imposto na conta de energia elétrica fora instituído pela Lei Estadual n $n^{0} 6.374$ de 1989, já no Paraná ocorrera através da Lei Estadual 11.580 de 1996. ${ }^{25}$

Às empresas concessionárias de fornecimento de energia, como a Eletropaulo e a Copel, concessionárias dos Estados de São Paulo e Paraná respectivamente, é dada a qualidade contribuinte legal e substituto tributário do supramencionado imposto, sendo que, dentro da área objeto da concessão, cabe a estas empresas realizar a tarefa de recolher o imposto ao erário estatal, referente às quantias cobradas nas Notas Fiscais da Conta de energia. ${ }^{26}$

\footnotetext{
${ }^{22}$ MACHADO, Hugo de Brito. Curso de direito constitucional tributário. São Paulo: Malheiros, 2012, p. 351.

${ }^{23}$ CARVALHO, Paulo de Barros. Direito tributário: fundamentos jurídicos da incidência. 9. ed. São Paulo: Saraiva, 2012, p. 243.

${ }^{24}$ SILVEIRA, Paulo Antônio Caliendo Velloso da. op. cit., p. 319.

${ }^{25}$ Assembleia Legislativa do Estado do Panará: Lei Estadual no 11.580 de 1996. Disponível em: <http://www. sefanet.pr.gov.br/SEFADocumento/Arquivos/7200511580.pdf > . Acesso em: 21 jun. 2015.

${ }^{26}$ ELETROPAULO. Banco de dados. Disponível em: < https://www.aeseletropaulo.com.br/para-sua-casa/prazos -e-tarifas/conteudo/impostos-e-outros-encargos > . Acesso em: 21 jun. 2015.
} 
O Convênio ICM 66/88 realizado entre os Estados e o Distrito Federal fixou as normas e firmou o entendimento sobre a base de cálculo do ICMS. Assim, restou determinado que o imposto deve ser calculado através de uma fórmula fornecida pelo Departamento Nacional de Águas e Energia Elétrica, sendo ela: ICMS = Fornecimento $\mathrm{x}$ [1/(1-Alíquota) $]-1 .^{27}$

A alíquota no Estado do Paraná fora fixada em 29\%, sendo que, conforme estabelece a Concessionária de Energia Elétrica do Paraná (COPEL), a base do Cálculo do ICMS se determina pela seguinte expressão: A x T x 100/71, onde "A" representa o consumo de energia; "T" significa na Tarifa sem o ICMS; e a Alíquota é de 29,00\%,

Vale mencionar que as alíquotas do ICMS dependem, na verdade, da variação do consumo de energia elétrica. Assim, quanto menor o consumo, menor será a alíquota da base de cálculo.

Para a classe residencial urbana cujo consumo mensal for até $150 \mathrm{kWh}$, a alíquota cobrada é de $12 \%$ sobre a base de cálculo do ICMS. Ultrapassada a quantia mensal de 150 $\mathrm{kWh}$, o consumidor urbano arcará com alíquota de $25 \%$ sob o montante excedido. ${ }^{28}$

Já para a classe rural, o consumo mensal de até $500 \mathrm{kWh}$ impõe a cobrança da alíquota mínima, ou seja, de $12 \%$ sobre a base de cálculo do ICMS, entretanto sob a quantia excedida será cobrada a alíquota de $25 \%{ }^{29}$

Assim, resta evidenciado que o ICMS é grande parte da receita dos Estados, e boa parte desta receita vêm da conta de luz dos cidadãos, fazendo com que a majoração ou diminuição da tarifa da energia elétrica possibilita uma alteração significativa das receitas estaduais.

\section{A TARIFA DE ENERGIA ELÉTRICA E SEUS REFLEXOS NOS ORÇAMENTOS ESTA- DUAIS}

No início de 2013 o Governo Federal confirmou a redução na conta de luz, impondo um corte de $18 \%$ para a tarifa de energia nas residências, e em até $23 \%$ para as indústrias. $^{30}$

\footnotetext{
${ }^{27}$ Idem.

${ }^{28}$ COPEL. Banco de dados. Disponível em: < http://www.copel.com/hpcopel/root/nivel2.jsp?endereco=\%2Fhpcope1\%2Froot\%2Fpagcopel2.nsf\%2F5d546c6fdeabc9a1032571000064b22e\%2Fb2f4a2f0687eb6cf03257488005939b9>. Acesso em: 21 jun. 2015.

${ }^{29}$ Idem.

${ }^{30}$ GLOBO. Dilma confirma redução na conta de luz e critica 'pessimistas'. Disponível em: < http://g1.globo.com/ economia/noticia/2013/01/dilma-confirma-reducao-na-conta-de-luz-e-critica-pessimistas.html $>$. Acesso em: 22 jun. 2015.
} 
Desta forma, ato contínuo com a diminuição da tarifa da energia elétrica houve forte baixa na base arrecadatória dos governos estaduais, eis que parte de seus balanços orçamentários possui como origem a arrecadação tributária de ICMS das contas de energia elétrica.

O fator supramencionado fez com que os Estados tivessem que tomar medidas imediatas para controlar as contas estaduais, e o Paraná, por exemplo, começou a anunciar o aumento do ICMS em diversos produtos na indústria regional. $^{31}$

Evidencia-se, com isso, que há falha de mercado da externalidade advinda da redução da conta de energia elétrica, restando analisar se a mesma é positiva ou negativa.

No caso em questão verificou-se uma redução média de 20,2\% nas tarifas de energia elétrica, o que acabou provocando uma queda de arrecadação do Imposto sobre Circulação de Mercadorias e Serviços sobre energia elétrica em cada Estado do país. ${ }^{32}$

Conforme relatado no tópico anterior, o imposto da energia elétrica é calculado sobre o valor da conta de luz, incluindo os encargos, o que representa, em média, $9 \%$ da arrecadação de todos os impostos pelos Estados..$^{33}$

O Conselho Nacional de Política Fazendária informa que no Estado de São Paulo a arrecadação com ICMS possui grande fatia representada pela cobrança na energia elétrica, representando 7,5\% da arrecadação total, já em outros Estados a arrecadação com ICMS na energia elétrica chega a $17 \%$.

Portanto, resta claro que a medida que minimizou o custo das tarifas cobradas nas contas de energia elétrica teve impacto significativo na capacidade de arrecadação de todos os Estados brasileiros. Neste sentido destacam-se as palavras de Marta Watanabe:

O consultor Clóvis Panzarini, ex-coordenador de administração tributária da Secretaria de Fazenda do Estado de São Paulo, diz que os governos estaduais devem perder quase que na mesma proporção a arrecadação do ICMS para consumidores finais como residências e comércio em geral. Nos casos das indústrias, porém, a perda deve ser relativizada, lembra Panzarini, porque a energia aplicada à produção gera créditos para a indústria. Como a indústria pagará menos ICMS

\footnotetext{
${ }^{31}$ GAZETA DO POVO. ICMS na indústria vai pesar no bolso. Disponível em: <http://www.gazetadopovo.com. br/economia/icms-na-industria-vai-pesar-no-bolso-eng2c9nciz96vi06ssaw1o5la > . Acesso em: 22 jun. 2015.

32 WATANABE, Marta. Arrecadação de ICMS cai com corte de tarifas. Valor Econômico. Disponível em: < http:// www.redenergia.com/noticias/arrecadacao-de-icms-cai-com-corte-de-tarifas/. > Acesso em: 22 jun. 2015.

33 Idem.
} 
pela energia aplicada na produção, ficará com menos crédito e terá débito maior, com mais imposto a pagar.

O consultor tributário Pedro César da Silva diz que, no caso da indústria, também há outras variáveis. "Se a indústria possuir muito saldo credor o efeito é outro.” No comércio, diz Panzarini, não há esse efeito, já que a energia não é considerada pelos Estados como insumo que dá direito a crédito do imposto. Trinchão diz, porém, que a medida é positiva. "Nós, como participantes, queremos ver o país crescer e é importante reduzir o valor da energia. Isso vai melhorar a competitividade." ${ }^{34}$

Portanto, conforme podemos notar, houve de fato um aumento da cobrança de ICMS pelos Estados, pois precisaram neutralizar o corte proveniente da medida governamental que reduziu a conta da energia elétrica. Por outro lado, diminuindo a conta de energia, há maior incentivo à atividade econômica, gerando, por conseguinte, mais arrecadação de ICMS pela venda de produtos.

Assim verificamos que o consumidor, por utilizar menor quantia de seu orçamento com o pagamento das contas de energia elétrica, acaba destinando o montante excedente na aquisição de serviços e produtos do comércio em geral, incendiando, assim, a economia como um todo.

Em termos de externalidade, tem-se que a relação econômica se deu entre o Governo Federal e as Concessionárias de Energia, sendo que os Estados, terceiros alheios à relação supracitada, acabaram sofrendo as consequências indiretas, pois perceberam a diminuição em suas arrecadações de ICMS provenientes da energia elétrica. Ademais, é possível pontuar que os consumidores da energia elétrica também podem ser apontados como terceiros que sofreram efeitos, restando averiguar se a externalidade notada é, de fato, positiva ou negativa.

De imediato percebe-se a presença de externalidade negativa, pois, como já mencionado, houve drástica queda na arrecadação de ICMS advindo da conta de energia elétrica. Assim, os Estados, ao menos inicialmente, tiveram menores arrecadações e tiveram que drenar investimentos em diversos setores sociais como na educação, saúde e infraestrutura.

Posteriormente os Estados passaram a majorar o ICMS de outros produtos e serviços, como foi o caso dos alimentos, bicicletas, brinquedos, materiais de limpeza, artefatos de uso doméstico, papelaria e instrumentos musicais, aumentando o valor pago pelo consumidor final. ${ }^{35}$

${ }^{34}$ Idem.

35 RIOS, Cristina. ICMS na Indústria vai pesar no bolso. Gazeta do Povo, 10 de fev. de 2014. Disponível em: $<$ http://www.gazetadopovo.com.br/economia/conteudo.phtml?id=1446073> . Acesso em: 22 jun. 2015. 
Confirma-se, portanto, a existência de externalidade negativa, todavia a medida federal ainda deve ser verificada sob os efeitos futuros, e não apenas imediatistas, fazendo com que seja verificada a possibilidade de existência da externalidade positiva.

Isso se faz perceptível pelo fato de que o corte na conta de energia faz com que a indústria se encoraja a realizar investimentos, pois gastará menos com energia elétrica. É um clássico exemplo de fomento indireto e que faz com que a atividade econômica se desenvolva e aumente a concorrência, o que é benéfico ao consumidor e ao próprio mercado.

É perceptível, ainda, que o incremento da atividade econômica faz com que haja maior arrecadação de ICMS pelos Estados, pois tal imposto também é cobrado sobre os produtos produzidos e alienados, fazendo com que o montante não arrecadado pela minoração da tarifa energética passe a ser percebido pelo aumento da atividade econômica em outros setores da economia.

O dinheiro que antes era utilizado para custear a conta da energia elétrica passou a ser realocado para aquisições de outros bens e serviços, fomentando a economia local e incentivando maiores investimentos na indústria local.

Vale destacar que a alíquota de ICMS cobrada na conta de energia é menor do que a alíquota nos demais produtos e serviços, verificando, novamente, a externalidade positiva da medida federal, pois aumenta a arrecadação do Estado, fomenta a economia e incrementa o consumo dos cidadãos.

Assim, analisando as implicações e consequências da diminuição da tarifa de energia elétrica, verifica-se que o benefício social é maior que o custo social da medida, pois tanto os cidadãos como os Estados são beneficiados no longo prazo dessa medida.

Ocorre que a acertada decisão federal em reduzir a conta de energia elétrica não durou muito tempo, pois a estimativa do Banco Central é de que no final de 2015 a energia elétrica suba 38\%. Essa estimativa tem como pressuposto o fato de o Governo Federal ter anunciado no início deste ano que "não pretende mais fazer repasses à Conta de Desenvolvimento Energético (CDE) em 2015, e os custos passam para os consumidores". ${ }^{36}$

Vale mencionar que no início de março de 2015 as contas de luz já haviam

\footnotetext{
${ }^{36}$ MARTELLO, Alexandro. Energia elétrica deve subir 38,3\% neste ano, estima o Banco Central. Disponível em: $<$ http://g1.globo.com/economia/noticia/2015/03/energia-eletrica-deve-subir-383-neste-ano-estima-banco-central.html>. Acesso em: 30 jun. 2015.
} 
sido elevadas, em média, mais de $23 \%$, pois houve uma revisão extraordinária das tarifas de energia elétrica e a mesma fora aprovada pela Aneel. O Paraná foi o Estado que teve maior reajuste, sendo que seus consumidores verificaram um incremento de $36 \%$ na conta da Copel, distribuidora de energia estadual. ${ }^{37}$

Como se vê, a redução da tarifa de energia elétrica ocorrida no início de 2013 durou um breve período, fazendo com que retornássemos ao status quo ante, demonstrando que a medida governamental que diminuiu a conta de energia elétrica em 2013 mais pareceu como uma política eleitoreira do que uma política pública em benefício do Estado Nacional.

\section{CONSIDERAÇÕES FINAIS}

Como exposto, o sistema econômico da autonomia é o modelo ideal a ser adotado pelos países, pois há uma clara divisão entre o setor político e o setor econômico, sendo que o pressuposto psicológico do espírito hedonista é capaz de proporcionar um melhor emprego dos insumos e das técnicas, onde a tomada de decisões realizadas pelos particulares justifica a livre atuação do mercado.

Ocorre que tanto os ortodoxos como os heterodoxos aceitam o fato de que o mercado pode ter falhas, tornando-se ineficiente e justificando a atuação estatal para controle e regulação.

Dentre as falhas de mercados existentes, destaca-se a externalidade, sendo esta definida como sendo o efeito, tanto positivo (benefício), quanto que negativo (custo), causado a um terceiro que esteja fora da relação econômica originária.

Assim, é necessário compreender que a decisão federal que reduziu a energia elétrica em janeiro de 2013 gerou a falha de mercado da externalidade, tanto com efeito positivo como negativo.

Primeiramente, destaca-se a presença de externalidade negativa, eis que houve uma queda na arrecadação de ICMS proveniente da conta da energia elétrica, fazendo com que houvesse, naquele momento, menos verbas para investimentos estaduais. Ademais, verifica-se um custo social o fato de os Estados terem aumentado a alíquota do ICMS em diversos produtos e serviços para compensar as perdas

\footnotetext{
${ }_{37}$ AMATO, Fábio. Contas de luz sobem, em média, 23,4\% no país a partir desta segunda. Disponível em: <http:// g1.globo.com/economia/noticia/2015/03/contas-de-luz-sobem-em-media-234-no-pais-partir-desta-segunda. html >. Acesso em: 30 jun. 2015.
} 
oriundas da redução da conta da energia.

Ocorre que um estudo aprofundado verifica que também há externalidades positivas, pois a redução da conta da energia faz com que haja um fomento indireto para que as empresas invistam em sua atividade econômica, aumentando a concorrência e e o consumo, pois os cidadãos deixaram de gastar tal montante na conta de luz, o que gera maior arrecadação de ICMS, pois em tais produtos também há incidência desse imposto.

Assim, é possível afirmar que o benefício social da redução da conta de energia elétrica, quando analisado em seus efeitos futuros, possuía todos os requisitos para ser maior que o próprio custo social da medida.

Ocorre que inexplicavelmente a minoração da conta de luz durou poucos meses, pois logo no início de 2015 os cidadãos brasileiros se depararam com aumentos sucessivos da energia elétrica, fazendo com que tivessem que reduzir drasticamente os gastos em outros produtos e serviços para conseguir adimplir com a conta de luz.

Infelizmente as políticas públicas brasileiras visam apenas benefícios de curto prazo, não existindo efetividade e nem a busca por uma mudança real e significativa. O sistema eleitoral nacional faz com que mudanças necessárias sejam postergadas e faz com que a economia nacional seja prisioneira das maléficas falhas de mercado e de sua consequente intervenção estatal.

\section{REFERÊNCIAS}

AMATO, Fábio. Contas de luz sobem, em média, 23,4\% no país a partir desta segunda. Disponível em: < http://g1.globo.com/economia/noticia/2015/03/contasde-luz-sobem-em-media-234-no-pais-partir-desta-segunda.html $>$. Acesso em: 30 jun. 2015.

Assembleia Legislativa do Estado do Panará: Lei Estadual no 11.580 de 2009. Disponível em: <http://www.sefanet.pr.gov.br/SEFADocumento/ Arquivos/7200511580.pdf $>$. Acesso em: 21 jun. 2014.

BRASIL. ANEEL. Sumário - lista de siglas. Disponível em: < http://www.aneel.gov. br/aplicacoes/atlas/sumario/siglas.htm > . Acesso em: 30 jun. 2015. 
BRESSER-PEREIRA, Luiz Carlos. Sistema Econômico Brasileiro. Conjuntura Econômica. Ed. Abril, 2005.

CARVALHO, Paulo de Barros. Direito tributário: fundamentos jurídicos da incidência. 9. ed. São Paulo: Saraiva, 2012, p. 243.

COPEL. Banco de dados. Disponível em: < http://www.copel.com/hpcopel/root/ nivel2.jsp?endereco=\%2Fhpcopel\%2Froot\%2Fpagcopel2.nsf\%2F5d546c6fdeabc9a1032571000064b22e\%2Fb2f4a2f0687eb6cf03257488005939b9>.Acesso em: 21 jun. 2015.

ELETROPAULO. Banco de dados. Disponível em: < https://www.aeseletropaulo. com.br/para-sua-casa/prazos-e-tarifas/conteudo/impostos-e-outros-encargos $>$. Acesso em: 21 jun. 2015.

IORO, Jorge Ubiratan. Economia e Liberdade: a escola Austríaca e a economia brasileira. Cap. 5. Falhas de Mercado Versus Falhas de Governo. Disponível em: < http://www.mises.org.br/SearchByAuthor.aspx?id=192>. Acesso em: 15 jun. 2015.

MACHADO, Hugo de Brito. Curso de direito constitucional tributário. São Paulo: Malheiros, 2012.

MANKIW, Gregory. Introdução à economia. São Paulo: Thompson Learning, 2007.

MARTELLO, Alexandro. Energia elétrica deve subir 38,3\% neste ano, estima o Banco Central. Disponível em: < http://g1.globo.com/economia/noticia/2015/03/ energia-eletrica-deve-subir-383-neste-ano-estima-banco-central.html $>$. Acesso em: 30 jun. 2015.

NEVES, Luís Gustavo Bregalda. Sistemas Econômicos e a Era Moderna. Disponível em: < http://www.mundojuridico.adv.br/sis_artigos/artigos.asp?codigo=288>. Acesso em: 12 jun. 2015.

NUSDEO, Fábio. Curso de Economia: introdução ao Direito Econômico. 7. ed. rev. atual. e ampl. São Paulo: Revistas dos Tribunais, 2013. 
RIOS, Cristina. ICMS na Indústria vai pesar no bolso. Gazeta do Povo, $10 \mathrm{de}$ fev. de 2014. Disponível em: < http://www.gazetadopovo.com.br/economia/conteudo. phtml?id=1446073> . Acesso em: 22 jun. 2015.

SEIDENFELD, Mark. Microeconomics Predictates to Law and Economics. Ohio: Anderson Publishing Co, 1996.

SECRETARIA DA FAZENDA DO ESTADO DE SÃO PAULO. Banco de dados. Disponível em: < http://www.fazenda.sp.gov.br/oquee/oq_icms.shtm>. Acesso em: 19 jun. 2015.

SILVEIRA, Paulo Antônio Caliendo Velloso da. Direito tributário e análise econômica do direito: uma visão crítica. Rio de Janeiro: Elsevier, 2009.

THE RONALD COASE INSTITUTE. Biografia. Disponível em: < https://www.coase. org/aboutronaldcoase.htm > . Acesso em: 19 jun. 2015.

WATANABE, Marta. Arrecadação de ICMS cai com corte de tarifas. Valor Econômico. Disponível em: http://www.redenergia.com/noticias/arrecadacao-de-icms-cai-comcorte-de-tarifas/ Acesso em: 22 jun. 2015.

Recebido em:09 de julbo de 2015 Aceito em: 18 de setembro de 2015 